\title{
MicroRNA en enfermedades autoinmunes
}

\author{
Isidro Alemán-Ávila, ${ }^{1,2}$ Daniel Cadena-Sandoval, ${ }^{1}$ Mayra Jiménez Morales ${ }^{1}$ y Julián Ramírez-Bello ${ }^{1}$ \\ 'Secretaría de Salud, Hospital Juárez de México, Unidad de Investigación en Enfermedades Metabólicas y Endocrinas, Ciudad de México, \\ México; ${ }^{2}$ Instituto Politécnico Nacional, Escuela Superior de Medicina, Programa de Maestría en Ciencias de la Salud
}

\section{Resumen}

Los microRNA (miRNA) son pequeños RNA no codificantes de aproximadamente 17 a 24 nucleótidos de longitud, los cuales se unen complementaria y principalmente en las regiones 3' UTR (región no traducida) de diversos RNA mensajeros (mRNA, messenger RNA). Su función general es regular negativamente la expresión génica a nivel postranscripcional, inhibiendo la traducción. Perfiles de expresión de miRNA alterados han sido identificados en diferentes líquidos, células y tejidos humanos afectados con diversas enfermedades autoinmunes y algunos se han propuestos potencialmente como biomarcadores de diagnóstico, pronóstico, actividad, etcétera, en estas patologías. Adicionalmente, variantes comunes del genoma humano, denominados polimorfismos de un solo nucleótido (SNP, single nucleotide polymorphisms) localizados en genes de miRNA han sido asociados con susceptibilidad, gravedad, y actividad en estas enfermedades. El objetivo de esta revisión es describir la biogénesis de los miRNA, su función, así como los perfiles de expresión y SNP en genes de miRNA asociados con diversas enfermedades autoinmunes, incluyendo tiroiditis autoinmune (tiroiditis de Hashimoto y enfermedad de Graves), lupus eritematoso sistémico, artritis reumatoide y síndrome de Sjögren primario.

PALABRAS CLAVE: MicroRNA. Inflamación. Autoimunidad. Expresión génica. Polimorfismos de un solo nucleótido.

\begin{abstract}
MicroRNAs (miRNAs) are small non-coding RNAs of approximately 17-24 nucleotides in length, which complementarily and mainly bind in 3' UTR (untranslated region) regions of different messenger RNAs (mRNAs). Their general function is to negatively regulate gene expression at the posttranscriptional level, thus inhibiting translation. miRNA abnormal expression profiles of have been found in different human fluids, cells and tissues affected by different autoimmune diseases, and some of them have been proposed as potential biomarkers of diagnosis, prognosis, activity etc. in these pathologies. In addition, common variants of the human genome, called single-nucleotide polymorphisms (SNPs), located within miRNA genes, have been associated with susceptibility, severity and activity in these diseases. The purpose of this review is to describe miRNA biogenesis and function, as well as the expression profiles and SNPs in miRNA genes that are associated with different autoimmune diseases, including autoimmune thyroiditis (Hashimoto $\square$ s thyroiditis and Graves $\square$ disease), systemic lupus erythematosus, rheumatoid arthritis and primary Sjögren's syndrome.
\end{abstract}

KEY WORDS: MicroRNA. Inflammation. Autoimmunity. Gene expression. Single-nucleotide polymorphisms.

Correspondencia:

Julián Ramírez-Bello

E-mail: dr.julian.ramirez.hjm@gmail.com
Fecha de recepción: 20-07-2017

Fecha de aceptación: 18-01-2018

DOI:10.24875/GMM.18003591
Gac Med Mex. 2019;155:63-71

Disponible en PubMed www.gacetamedicademexico.com 


\section{Introducción}

Los MicroRNA (miRNA) son pequeños RNA no codificantes (ncRNA, non-coding ribonucleic acids) de cadena sencilla de aproximadamente 17 a 24 nucleótidos de longitud, cuya función principal es regular negativamente a nivel postranscripcional la expresión de genes que codifican proteínas, mediante su hibridación con secuencias complementarias localizadas en las regiones 3' no traducidas (UTR, unstranslated regions) de RNA mensajeros (mRNA, messenger ribonucleic acids), e inhibir su traducción o disminuir su vida media., ${ }^{1,2}$ A nivel celular, los miRNA regulan múltiples procesos biológicos normales en las células del sistema inmune e incluye activación/inactivación, proliferación, diferenciación, apoptosis, inflamación y autoinmunidad, entre otros. ${ }^{2-5}$ Por ejemplo, el miRNA-155 (miR-155) promueve inflamación al inducir la activación de células $T$ y el miR-146a inhibe la respuesta inmune al inactivar células $T ;{ }^{6}$ ambos efectos demuestran su participación en la regulación del sistema inmunológico, inflamación y autoinmunidad, y las alteraciones en sus niveles de expresión contribuyen al desarrollo de enfermedades autoinmunes, como tiroiditis autoinmune -la cual se divide en tiroiditis de Hashimoto y enfermedad de Graves, lupus eritematoso sistémico (LES), artritis reumatoide (AR), y síndrome de Sjögren primario (SSP). Adicionalmente, variantes tipo polimorfismos de un solo nucleótido (SNP, single nucleotide polymorphisms), localizadas en algunos genes de miRNA han mostrado una asociación con susceptibilidad para algunas enfermedades autoinmunes. ${ }^{7,8}$ Por sus diferentes características: moléculas estables, ampliamente distribuidas en diferentes líquidos, células, tejidos, etcétera, que se sobre o subexpresan en condiciones de patología, y que esta expresión es específica de estadios de enfermedad, etcétera, los miRNA han sido propuestos como biomarcadores de diagnóstico, pronóstico, gravedad y actividad, en diversas enfermedades autoinmunes..$^{9-11}$ El objetivo de esta revisión es describir la biogénesis de los miRNA, su función, los perfiles de expresión alterados y SNP en genes de miRNA asociados con tiroiditis autoinmune (enfermedad de Graves y tiroiditis de Hashimoto), LES, AR y SSP.

\section{Biogénesis de miRNA}

La expresión génica de los miRNA se da mediante dos formas:
- Dependiente del promotor del gen donde residen.

- Dependiente de su propio promotor.

La RNA polimerasa II y factores generales de la transcripción son las principales proteínas que originan los transcritos primarios de los miRNA (pri-miRNA, primary miRNA), los cuales tienen una longitud de aproximadamente 4 kilobases. ${ }^{12} \mathrm{~A}$ los pri-miRNA recién sintetizados se les adiciona en su extremo $5^{\prime}$ una Cap (7-metil-guanosina), y en su extremo $3^{\prime}$ una cola de poliadeninas. Los pri-miRNA son procesados en el núcleo por la acción del complejo "microprocesador", el cual consta de la enzima con actividad de RNasa III; Drosha y una proteína con dominios de unión para RNA de doble cadena, llamada DGCR8 (DiGeorge syndrome chromosomal region 8, microprocessor complex subunit). Este complejo se encarga de eliminar los extremos $5^{\prime}$ y $3^{\prime}$ de la hebra de una sola cadena (ssRNA, single stranded $R N A$ ) de los pri-miRNA y originar miRNA precursores (pre-miRNA, precursor-miRNA) de aproximadamente 60 a 70 pares de bases..$^{12}$ Posteriormente, los pre-miRNA se transportan del núcleo al citoplasma a través de la proteína exportina 5 , la cual ejecuta su función por la energía proporcionada por Ran-GTPasa. ${ }^{13}$ En el citoplasma, los pre-miRNA son reconocidos por diferentes dominios de la enzima Dicer; el dominio PAZ (Piwi/Argonaute/Zwile) tiene como función reconocer y unirse al RNA de doble cadena (dsRNA, doble stranded RNA), mientras que los dos dominios de RNasa III cortan las cadenas de los pre-miRNA dando como resultado una estructura de RNA de doble cadena de aproximadamente 21 pares de bases. El RNA dúplex recién generado interactúa con un complejo multiproteico conocido como RISC (RNA-inducing silencing complex), el cual está constituido por las proteínas Dicer, TRBP (transactivation-response element RNA-binding protein) y Argonauta (Ago), esta última se une con la cadena del miRNA guía (estable), en tanto la otra cadena es pasajera y se degrada rápidamente (Figura 1). ${ }^{12}$

\section{Función de los miRNA}

En general, los miRNA se unen en las regiones 3' UTR de los mRNA (aunque también se pueden unir a las $5^{\prime}$ UTR) de dos maneras: por complementariedad perfecta y por complementariedad imperfecta. Entre los mecanismos propuestos de represión traduccional mediada por miRNA se encuentran los siguientes:

- Represión traduccional. Los miRNA se unen con su respectivo mRNA y evitan su traducción. Este 


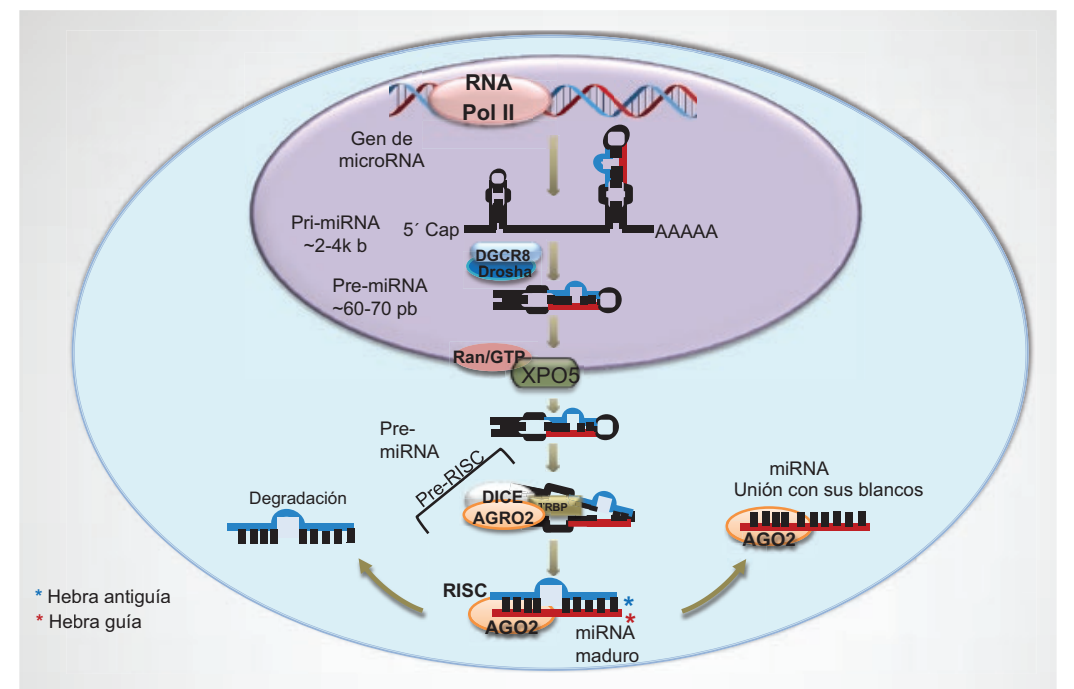

Figura 1. Biogénesis de miRNA. En este caso, los miRNA provienen de un gen de miRNA con su propio promotor. El miRNA se transcribe principalmente mediante la acción de la RNA polimerasa ll y factores generales de la transcripción, generando un miRNA primario (pri-miRNA) de aproximadamente 2 a 4 kilobases. La enzima Drosha que tiene actividad de RNasa III genera un precursor de miRNA (pre-miRNA) de aproximadamente 70 pares de bases en el núcleo celular. Posteriormente, este es exportado al citoplasma, donde es procesado mediante el complejo RISC (el cual tiene la enzima Dicer, la cual también tiene actividad de RNasa), generando un miRNA maduro que consiste de una doble hebra de RNA; la hebra guía se une a diversos mRNA blanco y la hebra antigua se degrada.

proceso se da por inhibición del inicio de la traducción, bloqueo de la elongación de la traducción y disociación prematura del complejo mRNA-ribosoma (Figura 2a).

- Degradación de los mRNA. En este proceso, los miRNA regulan la escisión/degradación de los mRNA blanco e inducen la eliminación de Cap y de-adenilación (Figura 2b).

Finalmente, la degradación de los miRNA se da por hidrólisis, lo que resulta casi en un completo silenciamiento de mRNA. En general, los miRNA no inhiben completamente la traducción de los mRNA, más bien reducen significativamente su expresión. ${ }^{14,15}$

\section{miRNA en autoinmunidad}

Diversos miRNA han sido asociados con el inicio, progresión, gravedad, etcétera, de varias enfermedades inflamatorias-autoinmunes debido a que regulan puntos clave de la respuesta inmunológica innata-adaptativa. Por ejemplo, el miR-146a regula negativamente la síntesis de diversas citocinas proinflamatorias y la proliferación de células del sistema inmunológico. ${ }^{16} \mathrm{Adi}$ cionalmente, en modelos murinos, su deleción se asocia con desregulación crónica de la vía NF-kB (nuclear factor-kappa $B$ ). Diversos estudios han mostrado que este miRNA tiene como blancos los 3' UTR de los mRNA: IRAK-1 (interleukin 1 receptor associated kinase 1), STAT1 (signal transducer and activator of transcription 1) y TRAF6 (TNF receptor associated factor 6), entre otros (proteínas de señalización celular involucradas en inflamación/autoinmundad) (Figura 3).

De esta manera, la subexpresión del miR-146a no regula negativamente de manera efectiva la expresión de IRAK1, STAT1, TRAF1, por consiguiente, hay un aumento de las citocinas TNF- $\alpha$ (tumor necrosis factor alpha) e IL-1ß (Figura 3), entre otras..$^{10,17}$ El knock-out de este gen conlleva la pérdida de regulación negativa de la síntesis de interferón tipo I en células dendríticas plasmacitoides y predispone a fenotipos autoinmunes. ${ }^{18,19}$

En células $T$, la deleción de Dicer (enzima que genera las formas maduras de los miRNA) en un estadio temprano de diferenciación, genera una reducción en el número de células T en órganos linfoides periféricos y timo. ${ }^{10,20}$ En estadios tempranos de las células $B$, la misma deleción resultó en un bloqueo de la transición de células pro a pre-B. ${ }^{10}$ Adicionalmente, el knock-out de Dicer en modelos murinos genera aumento en los títulos de autoanticuerpos y en los depósitos de complejos inmunes en secciones específicas del riñón. ${ }^{10}$ Otros estudios señalan que la deleción o sobreexpresión de ciertos miRNA resultan en daño en la tolerancia de células $B$ y aceleran el desarrollo de enfermedades autoinmunes. ${ }^{19-21}$ Estos datos indican que los miRNA desempeñan un papel crítico en la selección de linfocitos B-T y en el mantenimiento de la inmunotolerancia hacia antígenos propios. ${ }^{20}$ 


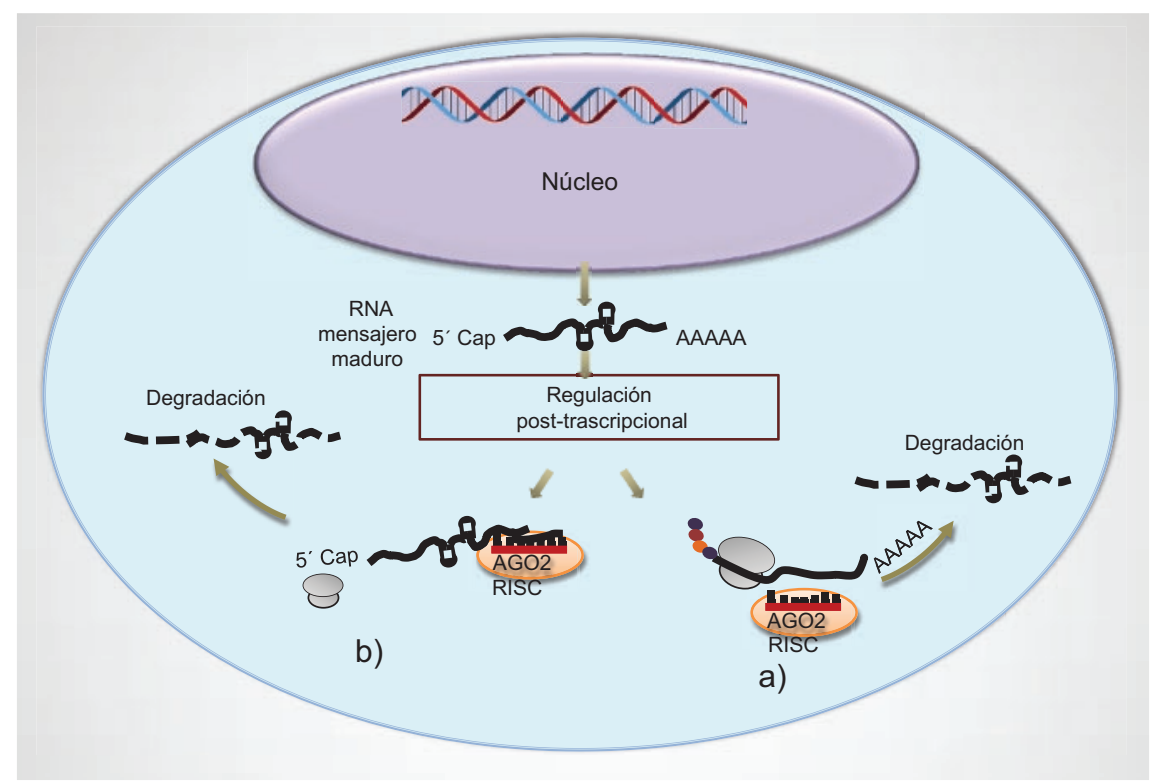

Figura 2. Función de los miRNA. A nivel postranscripcional, los miRNA regulan la degradación de sus mRNA blanco de dos maneras: a) a nivel de $m R N A$ Aribosomas $y$ b) degradando directamente sus $m R N A$ blanco, sin pasar por el ribosoma. La finalidad en ambos procesos es mediar la degradación de los miRNA mediante su unión con las regiones 3' UTR de los mRNA, dicha interacción media la hidrólisis de la hebra de los mRNA.

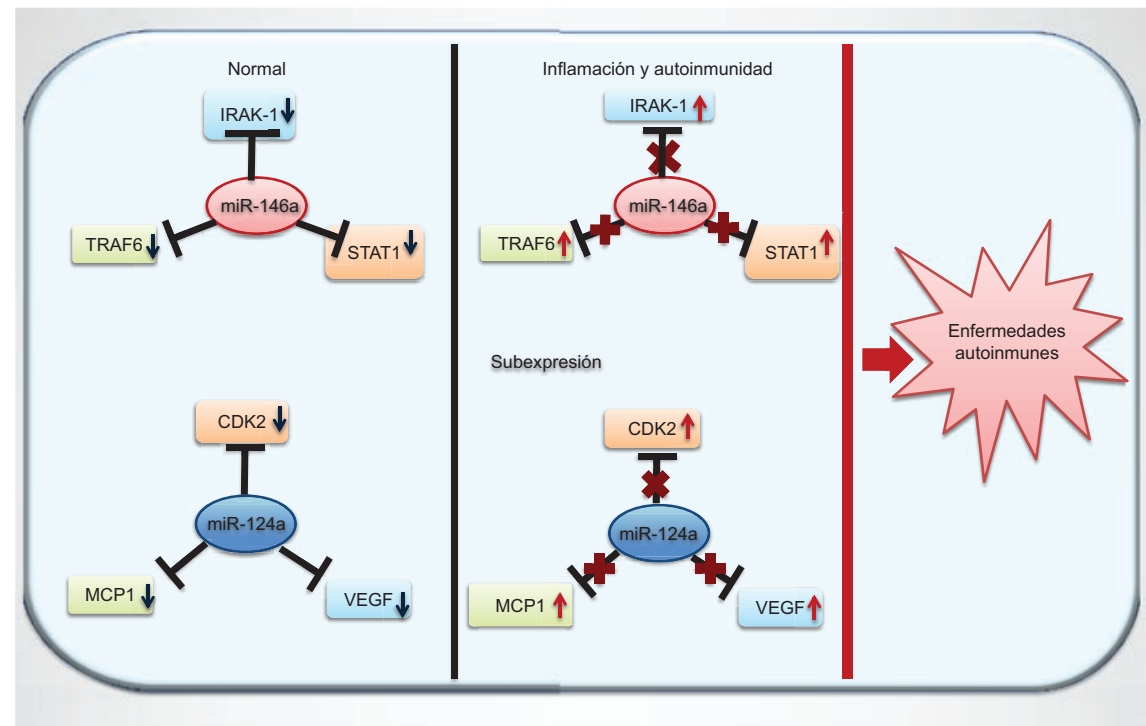

Figura 3. Efecto biológico de la subexpresión de los miR-146a y miR-124-3p en enfermedades y autoinmunes. La subexpresión de ambos miRNA (inhibidores IRF5, IRAK1, TRAF6, STAT1, CDK2, MCP1, VEGF, etcétera) conlleva a mayor cantidad de mRNA/proteínas de IRF5, IRAK1, TRAF6, STAT1, MCP1, VEGF, etcétera, proteínas involucradas en inflamación y autoinmunidad.

Por otro lado, diversos estudios genéticos han mostrado que la variabilidad tipo SNP localizados en algunos genes de miRNA contribuyen con susceptibilidad para desarrollar diversas enfermedades autoinmunes. ${ }^{22,23}$

\section{miRNA en tiroiditis autoinmune}

La tiroiditis autoinmune se caracteriza por ser una enfermedad autoinmune órgano específico de la tiroides y se divide en enfermedad de Graves y tiroiditis de Hashimoto. ${ }^{24}$ Diversos estudios han identificado perfiles de expresión de miRNA alterados en pacientes con tiroiditis autoinmune.

La enfermedad de Graves es causada por la producción excesiva de autoanticuerpos dirigidos contra diversos antígenos de la tiroides, uno de ellos, y que además representa el principal autoantígeno, es el receptor de la hormona estimulante de la tiroides. Los autoanticuerpos 
Tabla 1. Perfiles de expresión de miRNA alterados en pacientes con enfermedades autoinmunes

\begin{tabular}{|c|c|c|c|c|}
\hline \multirow[t]{2}{*}{ Enfermedad } & \multirow[t]{2}{*}{ Muestra } & \multicolumn{2}{|r|}{ Expresión } & \multirow[t]{2}{*}{ Referencias } \\
\hline & & Subexpresado & Sobreexpresado & \\
\hline \multirow[t]{2}{*}{ EG } & Suero & & $\begin{array}{l}\text { miR-16, miR-22, } \\
\text { miR-375, miR-451 }\end{array}$ & 27 \\
\hline & PBMC & miR-154, miR-376b, miR-431 & & 28 \\
\hline \multirow[t]{2}{*}{ TH } & Suero & & $\begin{array}{l}\text { miR-22, miR-375, miR-451 } \\
\text { miR-let-7e }\end{array}$ & 26 \\
\hline & PBMC & miR-125a-3p & & 34,35 \\
\hline \multirow[t]{2}{*}{ LES } & PBMC & $\begin{array}{l}\text { miR-196a, miR-17-5p, } \\
\text { miR-127-3p, miR-410 }\end{array}$ & $\begin{array}{l}\text { miR-21, miR-61, miR-78, miR-126, miR-142-3p, } \\
\text { miR-148a }\end{array}$ & 40,41 \\
\hline & Suero/plasma & $\begin{array}{l}\text { miR-125a, miR-130b-3p, } \\
\text { miR-17-5p, miR-112, miR-196a, } \\
\text { miR-155 }\end{array}$ & miR-223, miR-21, miR-126, miR-223 & $36-41$ \\
\hline \multirow[t]{3}{*}{ AR } & $\begin{array}{l}\text { Fibroblastos } \\
\text { sinoviales }\end{array}$ & $\begin{array}{l}\text { miR-124a, miR-34a } \\
\text { miR-21 }\end{array}$ & $\begin{array}{l}\text { miR-221, miR-146a, } \\
\text { miR-146b }\end{array}$ & 46,48 \\
\hline & PBMC & $\begin{array}{l}\text { miR-16, miR-125a-3p, miR-126-3p, } \\
\text { miR-132, }\end{array}$ & miR-16, miR-21, miR-24, miR-26a, miR-125a-5p & 46 \\
\hline & Plasma/suero & miR-146a & & 46 \\
\hline \multirow[t]{2}{*}{ SSP } & $\begin{array}{l}\text { PBMC } \\
\text { Glándulas salivales }\end{array}$ & & miR-146a, miR-155 & $51-52$ \\
\hline & $\begin{array}{l}\text { Tejido glandular } \\
\text { salivar }\end{array}$ & & miR-16, miR-181a & 53 \\
\hline
\end{tabular}

EG = enfermedad de Graves, $\mathrm{TH}=$ tiroiditis de Hashimoto, LES = lupus eritematoso sistémico, AR = artritis reumatoide, SSP = síndrome de Sjögren, PBMC = células mononucleares de sangre periférica.

contra este receptor estimulan y provocan que esta glándula produzca mayor cantidad de hormonas tiroideas tales como triyodotironina (T3) y tiroxina (T4), lo cual da como resultado hipertiroidismo autoinmune..$^{25}$

Estudios recientes han identificado niveles elevados de los siguientes miRNA en suero de pacientes con enfermedad de Graves: miR-16, miR-22, miR-375 y miR-451, entre otros ${ }^{26}$ (Tabla 1). En condiciones normales, miR-16 regula negativamente la expresión de la cinasa IKKa (kappa-B kinase subunit alpha), por lo tanto, su subexpresión durante la diferenciación de macrófagos correlaciona con un aumento de IKK $\alpha$, la cual fosforila a NF-kB y activa vías relacionadas con inflamación. ${ }^{27}$ Hasta ahora no se comprende porque este miRNA se encuentra sobreexpresado en suero de pacientes con enfermedad de Graves; ${ }^{26}$ son necesarios futuros estudios para comprender este hallazgo.

Por otro lado, se ha encontrado que los miR-154, miR-376b y miR-431 se encuentran subexpresados en células mononucleares de sangre periférica (PBMC) de pacientes con enfermedad de Graves (Tabla 1) de diagnóstico reciente y en pacientes con enfermedad de Graves en remisión se expresan nuevamente. Por lo tanto, la subexpresión de estos miRNA en PBMC podría inducir una respuesta inflamatoria en esta patología. ${ }^{28}$ Por otro lado, pacientes con enfermedad de Graves que han sido tratados durante años y continúan siendo positivos para autoanticuerpos han mostrado menores niveles de expresión de los miR-23b-5p y miR-92a-39 en suero en comparación con pacientes, mientras que miRNA let$7 g-3 p$ y miR-339-5p mostraron sobreexpresión (Tabla 1), por lo que estos ncRNA han sido propuestos como biomarcadores para monitorear o predecir la actividad de enfermedad de Graves. ${ }^{29}$

Algunos SNP localizados en genes de miRNA han sido asociados con esta enfermedad, uno de ellos, el polimorfismo rs3746444A/G del miR-499, localizado a nivel de pre-miRNA, no solo afecta su procesamiento sino también su expresión y unión con sus mRNA blancos. ${ }^{30}$ Recientemente se ha encontrado que el genotipo $A / G(R M=1.32, p=0.013)$ del rs3746444A/G del miR-499 se asoció con susceptibilidad para enfermedad de Graves (Tabla 2). Uno de los blancos de miR-499 es el receptor de IL-17 (IL-17RB). La reducción de la expresión de este miRNA lleva a aumento 
Tabla 2. Estudios de SNP en genes de miRNA y susceptibilidad para enfermedades autoinmunes

\begin{tabular}{lccccc}
\hline Enfermedad & miRNA & SNP & RM & p & Referencia \\
\hline EG & miR-499 & rs3746444A/G & 1.32 & 0.013 & 31 \\
TH & miR-125a & rs12976445C/T & 0.53 & 0.027 & 32 \\
LES & miR-146a & rs57095329A/G & 1.29 & 0.0001 & 41 \\
& & rs24311697C/T & 1.49 & 0.001 & 41 \\
AR & miR-499 & rs3746444A/G & 3.88 & 0.002 & 49
\end{tabular}

SNP = single nucleotide polymorphisms, $\mathrm{RM}=$ razón de momios, $\mathrm{EG}=$ enfermedad de Graves, $\mathrm{TH}=$ tiroiditis de Hashimoto, LES = lupus eritematoso sistémico, $\mathrm{AR}=$ artritis reumatoide.

de IL-17RB e IL-17, esta última, desempeña un papel determinante en la fisiopatología de diversas enfermedades autoinmunes. ${ }^{31}$ Por otro lado, Inoue et al. mostraron que el polimorfismo $\mathrm{rs} 12976445 \mathrm{C} / \mathrm{T}$ del miR-125a confiere susceptibilidad para enfermedad de Graves. ${ }^{32}$

Por otro lado, la tiroiditis de Hashimoto, también conocida como hipotiroidismo autoinmune, es causado por invasión de células linfoides sobre la glándula tiroides, las cuales provocan inflamación, atrofia gradual del tejido tiroideo e interfieren con su capacidad de producir hormonas tiroideas, resultando en hipotiroidismo. ${ }^{33}$

Respecto al papel de los miRNA en tiroiditis de Hashimoto, un estudio identificó niveles sobreexpresados de miR-22, miR-375 y miR-451 en suero (Tabla 1). ${ }^{26}$ En condiciones normales, miR-22 inhibe la señalización mediada por estrógenos y la expresión del receptor de estrógenos alfa (ER $\alpha$, estrogen receptor alpha), la sobreexpresión de este miRNA resulta en la represión de la vía de señalización estrógeno-ER $\alpha$, la cual es requerida para la diferenciación de células T, por lo tanto, su sobreexpresión afecta este proceso. ${ }^{27}$ Otro de los miRNA que ha mostrado sobreexpresión en PBMC de pacientes con tiroiditis de Hashimoto es el miR-let-7e, en tanto que el miR-125a-3p se ha encontrado subexpresado ${ }^{34,35}$ (Tabla 1).

En relación con la asociación entre variantes genéticas de miRNA y tiroiditis de Hashimoto, han sido realizados pocos estudios: dos mostraron que el SNP rs12976445C/T localizado en la secuencia del primiR-125a confiere protección para esta patología $\left(\mathrm{RM}=0.53, \mathrm{p}=0.027\right.$ ) (Tabla 2). ${ }^{30,32}$

\section{miRNA en LES}

LES representa el prototipo de las enfermedades autoinmunes, se caracteriza por afectar cualquier órgano, tejido o sistema debido al ataque de diversos autoanticuerpos dirigidos hacía antígenos nucleares o citoplasmáticos propios, tales como DNA, lípidos, ribonucleoproteínas, etcétera. Una citocina clave en LES es el interferón tipo I involucrado con un amplio rango de rasgos clínicos y actividad de la misma. ${ }^{36}$

Los miRNA más referidos en PBMC, suero, plasma o células $T$ y que se encuentran sobreexpresados en LES son miR-21, miR-61, miR-78, miR-126, miR-142-3p, miR-148a, miR-189, miR-410, miR-423-5p (Tabla 1), en tanto que los miR-146a, miR-125a, miR-155, miR-130b-3p, miR-17-5p, miR-196a, miR-184, etcétera, se han identificado subexpresados ${ }^{10,37-40}$ (Tabla 1). En condiciones normales, miR-126 se une al mRNA de la enzima DNA metiltransferasa 1, su sobreexpresión lleva a disminución de esta enzima, causando hipometilación en regiones de unión para esta proteína y una mayor expresión de los RNAm/proteínas CD11a y CD70, importantes en la patogénesis de LES. ${ }^{40}$ Por otra parte, en condiciones normales, el miR-155 inhibe la expresión del supresor 1 de la señalización de citocinas (SOCS1, supresor of cytokine signaling 1), el cual regula la fosforilación de STAT3. Un estudio reciente en PBMC de pacientes con LES identificó subexpresión de este miRNA, lo cual generó aumento en la expresión de SOCS1; en este mismo estudio se sobreexpresó al miR-155, lo cual generó disminución de SOCS1 y aumento de la fosforilación de STAT3, así como de la función de IL-21 (Figura 4). En el contexto de autoinmunidad, esta citocina actúa como un gen guardián de la proliferación de células B y diferenciación hacía células plasmáticas generadoras de autoanticuerpos. De esta manera, mayores cantidades de IL-21 (junto con otras citocinas) inducen proliferación de células B independiente de antígenos y aumentan la señalización mediada por el BCR. ${ }^{41}$

Dos estudios reportaron SNP en miR-146a asociados con LES. El SNP rs57095329A/G localizado en el promotor del miR-146a mostró asociación con susceptibilidad para LES en asiáticos (RM $=1.29$, $p=0.0001$ ) (Tabla 2). ${ }^{40}$ Adicionalmente, el SNP rs24311697C/T localizado entre el gen que codifica para la proteína transformante 1 de tumor pituitaria y el miR-146a también mostró asociación con susceptibilidad para LES (alelo T, RM $=1.23, p=0.001$; genotipo TT, RM = 1.49, $p=0.001$ ) (Tabla 2). ${ }^{41}$ Por otro lado, otros estudios indican que tanto el SNP rs2910164G/C localizado en el pre-miR-146a, como el rs3746444A/G de miR-499 no confieren susceptibilidad para LES. 42,43 


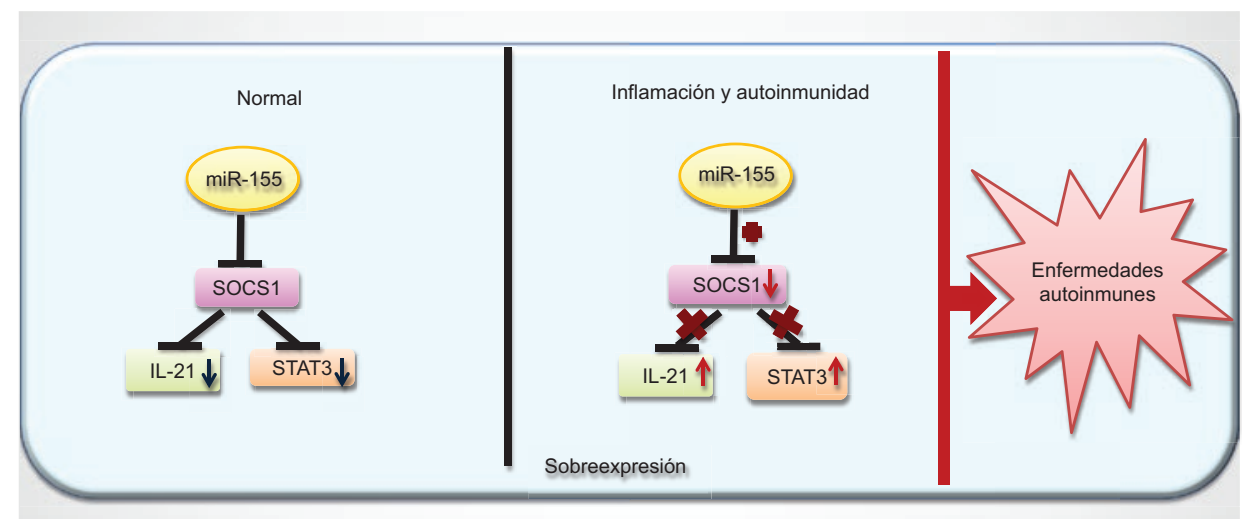

Figura 4. Efecto biológico de la sobreexpresión de miR-155 en enfermedades autoinmunes. La sobreexpresión de miR-155 conlleva a una menor cantidad de su mRNA blanco: SOCS1. De esta manera, este evento lleva a una menor expresión de SOCS1 y a una mayor expresión de IL-21 y STAT3.

\section{miRNA en AR}

AR es una enfermedad autoinmune sistémica, inflamatoria, crónica, caracterizada por inflamación de las membranas sinoviales con movimiento y destrucción articular, la cual causa deformidad, discapacidad del individuo afectado y se puede acompañar de diferentes manifestaciones extraarticulares. ${ }^{23}$

Diversos estudios han mostrado patrones de expresión de miRNA alterados en PBMC, linfocitos $T$, fibroblastos sinoviales, osteoclastos, líquido sinovial, etcétera, de pacientes con AR. ${ }^{44,45}$ Los miR-146a/b se han encontrado sobreexpresados en diferentes tipos celulares, tales como PBMC, fibroblastos sinoviales, tejido y líquido sinovial, etcétera. ${ }^{45}$ Estos datos deben tomarse con precaución, ya que en LES y en modelos murinos, la deleción o subexpresión de miR-146a conlleva a generar autoinmunidad espontánea o contribuye al desarrollo de LES, respectivamente: ${ }^{10,19}$ en diversos líquidos y células de pacientes con AR es difícil determinar un papel similar, dado que este miRNA se ha encontrado sobreexpresado y no subexpresado. Son necesarios futuros estudios para determinar su papel en AR. Otros miRNA sobreexpresados en plasma, líquido/tejido sinovial, PBMC o fibroblastos sinoviales de pacientes con AR son miR-16, miR-21, miR-24, miR-26a, miR-125b, miR-126-3p, miR-155, miR-221, miR-222 y miR-451 (Tabla 1); los miR-124a, miR-125a-3p, miR-126-3p, miR-132 y miR-155 se han encontrado subexpresados ${ }^{44,45}$ (Tabla 1). El miR-124a regula la expresión de cinasa-2 dependiente de ciclina (CDK2, cyclin-dependent kinase), proteína quimioatrayente de monocitos 1 (MCP1, monocyte chemoatractant protein 1) y del factor de crecimiento endotelial vascular (VEGF, vascular endothelial growth factor).
De esta manera, de acuerdo con sus blancos, miR124a regula proliferación, quimioatracción leucocitaria y angiogénesis, respectivamente en CDK-2, MCP-1 y VEGF. Por lo cual, su disminución lleva a una mayor expresión de CDK-2, MCP-1 y VEGF ${ }^{46}$. Por su parte, el miR-221 sobreexpresado en fibroblastos sinoviales aumenta la síntesis de citocinas proinflamatorias, promueve migración y resistencia para apoptosis. ${ }^{47}$

Respecto a la susceptibilidad genética en AR se ha reportado una asociación con el SNP rs3746444A/G del miR-499: genotipo AA vs. $G G, R M=3.88$, $p=0.002$, pero no del SNP rs2910164G/C del gen miR-146a, en iraníes ${ }^{48}$ (Tabla 2). Sin embargo, otro estudio mostró al polimorfismo rs3746444A/G de miR499 asociado con protección para AR (AA vs, AG; OR $0.3, p=0.005$ ) (Tabla 2), actividad de la enfermedad y toxicidad para metotrexato en población egipcia. El SNP rs11614913 del gen miR-196a2 no mostró asociación con AR en esta misma población. ${ }^{49}$

\section{miRNA en SSP}

El síndrome de Sjögren primario (SSP), una enfermedad autoinmune crónica, caracterizada por inflamación, infiltración linfocítica en las glándulas exocrinas, y afectación sobre todo de las bucales (xerostomía) y oculares (xeroftalmia), ocasionan resequedad. SSP también puede afectar órganos y sistemas como riñón, hígado, así como el sistema nervioso y el aparato circulatorio. ${ }^{50}$

Perfiles de expresión génica de miRNA alterados han sido identificados en SSP. Dos estudios han identificado una sobreexpresión del miR-146a en PBCM. ${ }^{51,52}$ Por otro lado, Gourzi et al. sugirieron que Ios miRNA 16, 181a, 200b, 200b*, 23 y 483-5p pueden 
predecir un mal pronóstico en esta enfermedad (Tabla 1). ${ }^{53}$ La elevada expresión de miR-16 y miR-181a han sido asociada con disminución en la función de las glándulas salivares pequeñas. ${ }^{53}$ Un reciente estudio mostró 25 diferentes miRNA sobreexpresados y uno subexpresado en pacientes con SSP en comparación con los controles; entre los sobreexpresados se encuentran let-7e-5p, miR-16-1-3p, miR-20b-5p, miR-21, miR-146a, miR-424-3p, miR-190a, miR-21-3p, entre otros, en tanto que el miR-150-5p se encontró subexpresado. ${ }^{54}$ Respecto a la susceptibilidad genética en SSP, hasta el momento no hay estudios reportados de polimorfismos en genes de miRNA.

\section{Conclusiones}

Los miRNA representan potencialmente nuevos blancos terapéuticos de interés en diversas áreas médicas, donde se incluyen las diversas enfermedades autoinmunes. Los miRNA contribuyen importantemente en la regulación de todos los procesos involucrados normales y patológicos del sistema inmunológico e incluye activación/inactivación, proliferación, diferenciación, síntesis de citocinas, etcétera. Perfiles de expresión alterados de diversos miRNA han sido identificados en enfermedad de Graves, tiroiditis de Hashimoto, AR, LES y SSP, entre otras. Varios de ellos han mostrado una sub o sobreexpresión, lo cual ha sido asociado con su desarrollo, mal pronóstico, gravedad, etcétera. Adicionalmente, variantes tipo de SNP localizados en genes de miRNA han mostrado asociación con susceptibilidad para desarrollar diferentes enfermedades autoinmunes. Sin embargo, pocos estudios han sido llevados a cabo en diversas poblaciones. Por lo cual, es necesario evaluar estas variantes en genes de miRNA en diferentes enfermedades autoinmunes y poblaciones. A pesar de los datos generados en estas patologías, debemos tomar los resultados con precaución, dado que varios estudios muestran datos controversiales. Es importante seguir estudiando el papel de estos miRNA y en mayor detalle en estas patologías para determinar sus papeles como posibles blancos terapéuticos 0 biomarcadores de pronóstico.

\section{Agradecimientos}

Los autores agradecen el financiamiento del CONACyT (FOSISS, proyecto 233107). Isidro Alemán-Ávila agradece a CONACyT la beca 651960, número de apoyo 453284, otorgada durante su estancia en la maestría.

\section{Bibliografía}

1. Mendell JT. MicroRNAs: critical regulators of development, cellular physiology and malignancy. Cell Cycle. 2005;4:1179-1184.

2. Ambros V. The functions of animal microRNAs. Nature. 2004;431:350-355.

3. Bernecker C, Lenz L, Ostapczuk MS, Schinner S, Willenberg H, Ehlers M, et al. MicroRNAs miR-146a1, miR-155 2, and miR-200a1 are regulated in autoimmune thyroid diseases. Thyroid. 2012;22:1294-1295.

4. Baltimore D, Boldin MP, O'Connell RM, Rao DS, Taganov KD. MicroRNAs: new regulators of immune cell development and function. Nat Immunol. 2008;9:839-845.

5. O'Connell RM, Rao DS, Chaudhuri AA, Baltimore D. Physiological and pathological roles for microRNAs in the immune system. Nat Rev Immunol. 2010;10:111-122.

6. Li K, Du Y, Jiang BL, He JF. Increased microRNA-155 and decreased microRNA-146a may promote ocular inflammation and proliferation in Graves' ophthalmopathy. Med Sci Monit. 2014;20:639-643.

7. Liu X, Han Z, Yang C. Associations of microRNA single nucleotide polymorphisms and disease risk and pathophysiology. Clin Genet. 2016;92:235-242.

8. Chatzikyriakidou A, Voulgari PV, Georgiou I, Drosos AA. miRNA and related polymorphisms in rheumatoid arthritis susceptibility. Autoimmun Rev. 2012;11:636-641.

9. Alevizos I, Illei GG. MicroRNAs as biomarkers in rheumatic diseases. Nat Rev Rheumatol. 2010;6:391-398.

10. Chen JQ, Papp G, Szodoray P, Zeher M. The role of microRNAs in the pathogenesis of autoimmune diseases. Autoimmun Rev. 2016;15: 1171-1180.

11- Marques-Rocha JL, Samblas M, Milagro FI, Bressan J, Martínez JA, Marti A. Noncoding RNAs, cytokines, and inflammation-related diseases. FASEB J. 2015;29:3595-3611.

12. UI Hussain M. Micro-RNAs (miRNA): genomic organisation, biogenesis and mode of action. Cell Tissue Res. 2012;349:405-413.

13. Bohnsack MT, Czaplinski K, Gorlich D. Exportin 5 is a RanGTP-dependent dsRNA-binding protein that mediates nuclear export of pre-miRNA. RNA. 2004:10:185-191.

14. Cannell IG, Kong YW, Bushell M. How do microRNAs regulate gene expression? Biochem Soc Trans. 2008;36:1224-1231.

15. Mohr AM, Mott JL. Overview of microRNA biology. Semin Liver Dis. 2015;35:3-11.

16. Lee HM, Kim TS, Jo EK. MiR-146 and miR-125 in the regulation of innate immunity and inflammation. BMB Rep. 2016;49:311-318.

17. Tang $Y$, Luo X, Cui H, Ni X, Yuan M, Guo Y, et al. MicroRNA-146a contributes to abnormal activation of the type I interferon pathway in human lupus by targeting the key signaling proteins. Arthritis Rheum. 2009;60:1065-1075

18. Boldin MP, Taganov KD, Rao DS, Yang L, Zhao JL, Kalwani M, et al. miR-146a is a significant brake on autoimmunity, myeloproliferation, and cancer in mice. J Exp Med. 2011;208:1189-1201.

19. Garo LP, Murugaiyan G. Contribution of microRNAs to autoimmune diseases. Cell Mol Life Sci. 2016;73:2041-2051.

20. Cobb BS, Nesterova TB, Thompson E, Hertweck A, O'Connor E, Godwin J, et al. T cell lineage choice and differentiation in the absence of RNase III enzyme Dicer. J Exp Med. 2005;201:1367-1373.

21. González-Martín A, Adams BD, Lai M, Shepherd J, Salvador-Bernaldez M, Salvador JM, et al. The microRNA miR-148a functions as a critical regulator of B cell tolerance and autoimmunity. Nat Immunol. 2016;17: 433-440.

22. Ramírez-Bello J, Jiménez-Morales S. Implicaciones funcionales de los polimorfismos (SNP) en genes codificantes de proteínas y no codificantes en enfermedades multifactoriales. Gac Med Mex. 2017;153:238-250.

23. Rodríguez-Elías AK, Maldonado-Murillo K, López-Mendoza LF, Ramírez-Bello J. Genetics and genomics in rheumatoid arthritis (RA): an update. Gac Med Mex. 2016;152:218-227.

24. Brown RS. Autoimmune thyroid disease: unlocking a complex puzzle. Curr Opin Pediatr. 2009;21:523-528.

25. Burch HB, Cooper DS. Management of Graves disease: a review. JAMA. 2015;314:2544-2554.

26. Yamada $\mathrm{H}$, Itoh $\mathrm{M}$, Hiratsuka I, Hashimoto $\mathrm{S}$. Circulating microRNAs in autoimmune thyroid diseases. Clin Endocrinol (Oxf). 2014;81:276-281.

27. Li T, Morgan MJ, Choksi S, Zhang Y, Kim YS, Liu ZG. MicroRNAs modulate the noncanonical transcription factor NF-kappaB pathway by regulating expression of the kinase IKKalpha during macrophage differentiation. Nat Immunol. 2010;11:799-805. 
28. Liu R, Ma X, Xu L, Wang D, Jiang X, Zhu W, et al. Differential microRNA expression in peripheral blood mononuclear cells from Graves' disease patients. J Clin Endocrinol Metab. 2012;97:E968-E972.

29. Hiratsuka I, Yamada H, Munetsuna E, Hashimoto S, Itoh M. Circulating microRNAs in Graves' disease in relation to clinical activity. Thyroid. 2016;26:1431-1440

30. Cai T, Li J, An X, Yan N, Li D, Jiang Y, et al. Polymorphisms in MIR499a and MIR125a gene are associated with autoimmune thyroid diseases. Mol Cell Endocrinol. 2017;440:106-115.

31. Singh RP, Hasan S, Sharma S, Nagla S, Yamaguchi DT, Wong DT, et al Th17 cells in inflammation and autoimmunity. Autoimmun Rev. 2014:13:1174-1181.

32. Inoue $\mathrm{Y}$, Watanabe M, Inoue N, Kagawa T, Shibutani S, Otsu H, et al Associations of single nucleotide polymorphisms in precursor-microRNA (miR)-125a and the expression of mature miR-125a with the development and prognosis of autoimmune thyroid diseases. Clin Exp Immunol. 2014;178:229-235.

33. Pyzik A, Grywalska E, Matyjaszek-Matuszek B, Roliński J. Immune disorders in Hashimoto's thyroiditis: what do we know so far? J Immunol Res. 2015;2015:979167.

34. Kagawa T, Watanabe M, Inoue N, Otsu H, Saeki M, Katsumata $Y$, et al. Increases of microRNA let-7e in peripheral blood mononuclear cells in Hashimoto's disease. Endocr J. 2016;63:375-380.

35. Peng H, Liu Y, Tian J, Ma J, Tang X, Yang J, et al. Decreased expression of microRNA-125a-3p upregulates interleukin-23 receptor in patients with Hashimoto's thyroiditis. Immunol Res. 2015;62:129-136.

36. Zan H, Tat C, Casali P. MicroRNA in lupus. Autoimmunity. 2014;47: 272-285.

37. Yan S, Yim LY, Lu L, Lau CS, Chan VS. MicroRNA regulation in systemic lupus erythematosus pathogenesis. Immune Netw. 2014;14:138-148.

38. Pan W, Zhu S, Yuan M, Cui H, Wang L, Luo X, et al. MicroRNA-21 and microRNA-148a contribute to DNA hypomethylation in lupus CD4+ T cell by directly and indirectly targeting DNA methyltransferase 1 . J Immunol. 2010;184:6773-6781.

39. Tang ZM, Fang M, Wang JP, Cai PC, Wang P, Hu LH. Clinical relevance of plasma miR-21 in new-onset systemic lupus erythematosus patients. J Clin Lab Anal. 2014;28:446-451.

40. Husakova M. MicroRNAs in the key events of systemic lupus erythematosus pathogenesis. Biomed Pap Med Fac Univ Palacky Olomouc Czech Repub. 2016;160:327-342

41. Rasmussen TK, Andersen T, Bak RO, Yiu G, Sørensen CM, Stengaard-Pedersen $\mathrm{K}$, et al. Overexpression of microRNA-155 increases IL-21 mediated STAT3 signaling and IL-21 production in systemic lupus erythematosus. Arthritis Res Ther. 2015;17:154.
42. Lee $\mathrm{YH}$, Bae SC. The miR-146a polymorphism and susceptibility to systemic lupus erythematosus and rheumatoid arthritis: a meta-analysis. Z Rheumatol. 2015;74:153-156.

43. Fu L, Jin L, Yan L, Shi J, Wang H, Zhou B, et al. Comprehensive review of genetic association studies and meta-analysis on miRNA polymorphisms and rheumatoid arthritis and systemic lupus erythematosus susceptibility. Hum Immunol. 2016;77:1-6.

44. Murata $K$, Furu $M$, Yoshitomi $H$, Ishikawa $M$, Shibuya $H$, Hashimoto $M$ et al. Comprehensive microRNA analysis identifies miR-24 and miR$125 a-5 p$ as plasma biomarkers for rheumatoid arthritis. PLoS One. 2013;8:e69118.

45. Churov AV, Oleinik EK, Knip M. MicroRNAs in rheumatoid arthritis: altered expression and diagnostic potential. Autoimmun Rev. 2015;14:1029-1037.

46. Nakamachi Y, Kawano S, Takenokuchi M, Nishimura K, Sakai Y, Chin T, et al. MicroRNA-124a is a key regulator of proliferation and monocyte chemoattractant protein 1 secretion in fibroblast-like synoviocytes from patients with rheumatoid arthritis. Arthritis Rheum. 2009;60:1294-1304.

47. Yang S, Yang Y. Downregulation of microRNA-221 decreases migration and invasion in fibroblast-like synoviocytes in rheumatoid arthritis. Mol Med Rep. 2015;12:2395-2401.

48. Hashemi M, Eskandari-Nasab E, Zakeri Z, Atabaki M, Bahari G, Jahantigh M, et al. Association of pre-miRNA-146a rs2910164 and pre-miR-499 rs3746444 polymorphisms and susceptibility to rheumatoid arthritis. Mol Med Rep. 2013;7:287-291.

49. Toraih EA, Ismail NM, Toraih AA, Hussein MH, Fawzy MS. Precursor miR499a variant but not miR-196a2 is associated with rheumatoid arthritis susceptibility in an Egyptian population. Mol Diagn Ther. 2016;20:279-295.

50. Alevizos I, Illei GG. MicroRNAs in Sjögren's syndrome as a prototypic autoimmune disease. Autoimmun Rev. 2010;9:618-621.

51. Zilahi E, Tarr T, Papp G, Griger Z, Sipka S, Zeher M. Increased microRNA-146a/b, TRAF6 gene and decreased IRAK1 gene expressions in the peripheral mononuclear cells of patients with Sjögren's syndrome. Immunol Lett. 2012;141:165-168.

52. Pauley KM, Stewart CM, Gauna AE, Dupre LC, Kuklani R, Chan AL, et al. Altered miR-146a expression in Sjögren's syndrome and its functional role in innate immunity. Eur J Immunol. 2011;41:2029-2039.

53. Gourzi VC, Kapsogeorgou EK, Kyriakidis NC, Tzioufas AG. Study of microRNAs (miRNA) that are predicted to target the autoantigens Ro/ SSA and La/SSB in primary Sjögren's Syndrome. Clin Exp Immunol. 2015;182:14-22.

54. Chen JQ, Papp G, Póliska S, Azabó K, Tarr T, Bálint BL, et al. MicroRNA expression profiles identify disease-specific alterations in systemic lupus erythematosus and primary Sjögren $\square$ s syndrome. PLoS One. 2017;12:e0174585. 